\title{
Principles of formation of mobile dwelling of cluster type with application of additive technologies
}

\author{
Alexander Panfilov ${ }^{1}$,Vladimir Panfilov, ${ }^{1, *}$ \\ ${ }^{1}$ Institute of Architecture and Design, Industrial University of Tyumen, 625001 Tyumen, Russian \\ Federation
}

\begin{abstract}
One of the most acute problems of modern society are issues related to the globalization of mankind caused by the next small scientific and technological revolution that is taking place and the emerging transition to a post-industrial society. Some of their characteristic features of this society are: deterritoriality, weakening of functional-spatial ties between places of residence, the application of labor and recreation rights. The peculiarity of the emerging new architecture with the arrival of the postindustrial information society is becoming completely new approaches to the formation of cities and the human dwelling itself. The article deals with the application of additive technologies in the production of mobile residential objects of high factory readiness. The article describes the concept of the formation of a mobile dwelling cluster type based on the principles of the organization of intelligent self-adapting systems (Smart Development), gives examples of author's developments in the field of cluster housing, with a description of the fundamental principles necessary for the possibility of further development and technical implementation.
\end{abstract}

One of the most burning issues of the modern society, along with ecology, social inequality and military conflicts, are issues of the globalization of mankind caused by the ongoing small scientific and technological revolution taking place and the emerging transition to a postindustrial society. Some of their characteristic features are: deterritoriality, weakening of functional-spatial connections between places of residence, and the application of labor and recreation [1-4]. It should be noted that with the change of society, there will also be a gradual change in human psychology in relation to the abovementioned problems. In the stage of changing human society, there is also a rethinking of approaches to the formation of the world order that surrounds man and, in particular, the surrounding architecture. This happened in Ancient Rome, in Medieval Europe, in each of the occurred scientific and technological revolutions.

The feature of the emerging new architecture with in the postindustrial information society is completely new approaches to the formation of cities, a new tectonics of the human dwelling itself [5-7]:

1. The residential cell is ceasing to be an integral structural part of the residential building, gaining an increasing degree of autonomy in providing energy and other resources.

\footnotetext{
* Corresponding author: archi-zoom@yandex.ru
} 
2. The residential cell requires to refuse of geographic attachment to the place of permanent deployment and the granting of it as freedom of movement, and universal systems of connection to engineering and other communications.

3. The outer contour of the residential cell, as well as its internal filling, should no longer be capital objects - they are light, informationally saturated, dynamically changing shells with a certain degree of adaptability.

4. Modern telecommunication and information networks allow a person to be in those places where his physical presence is not required, reducing the value of space, distance and attachment to one or several close places almost to zero. The idea of "remoteness" disappears, which is confirmed also by the words of the Director of the Paris Architectural School, Paul Verilio: "There are no more spaces!" [8], prophetically told them long before the present time.

5. Based on the first four features, a new - the fifth feature - follows: structural mobility. "Structural mobility" of a residential cell, unlike the usual "spatial mobility", means not only the possibility of spatial displacement, but also the saturation of a residential cell with such properties as:

- Interactivity of Interactions at the System "Home - nature - man";

- Versatility and Multiplicity of solutions that enable reflect infinitely of people activities in real mode Foot time;

- Dynamics and Variability - when it is possible to reconfigure residential cells as a function of changing the initial settings, external and internal conditions (it is significant that with the development of control systems based on artificial intelligence becomes possible transition to neural network Spatial modeling of objects);

- Multifunctionality as the possibility to change tasks Carried out Object or Separate him Parts without Making Cardinal Changes at him volumetric planning decision.

The answer to these challenges may be came the system model of a mobile transformed residential cell of the cluster type. This article deals with two issues related to its creation:

1. General description and main characteristics of the system.

2. Principal decisions related with its creation on the basis of additive technologies.

\section{General description and main characteristics of the system}

Considering the growing human need in global mobility, as well as the acceleration of dynamic life processes, it is proposed to consider the possibility of creating a model of a mobile transformable cluster-type residential cell (hereinafter: cluster mobile housing).

Mobile housing is a product of high factory readiness and relates to the housing construction industry and to machine building, and also to such its part that deals with transport systems and other means of transport. This related state of two independent areas of industrial production has been repeatedly noted in earlier author's publications and it is based on a study of the historical evolution of the human dwelling, mobile home and vehicles [9-11]. The difference between these system begins to gradually fade at the present 
stage of development of them. We can live in the car with equal comfort, as well as move in our own house. I will give some examples from the real practice of our time:

1. Volkner Mobil Performance [12]

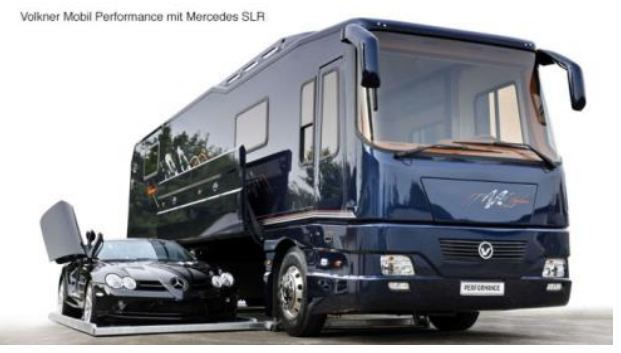

Fig. 1. Volkner Mobil Performance, general view

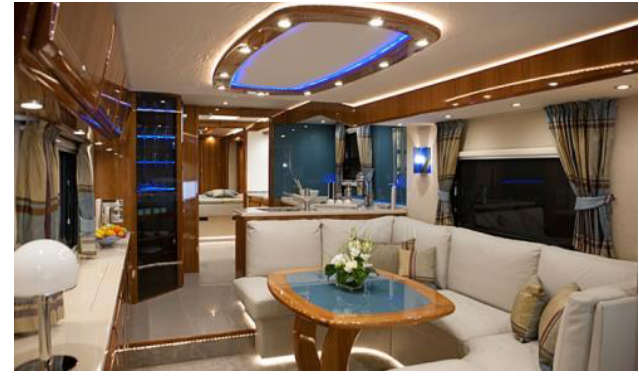

Fig. 2. Volkner Mobil Performance, option of interior solutions

This line of products of the company, belonging to the category of house-liners is not just a full-fledged three-room apartment, but a whole house with a garage with a degree of autonomy, reaching up to 1 week.

\section{Greenmoxie Tiny House [13]}

You can give another example of this solution: Greenmoxie Tiny House, this is not a machine, adapted for living - it's a house, put on wheels.

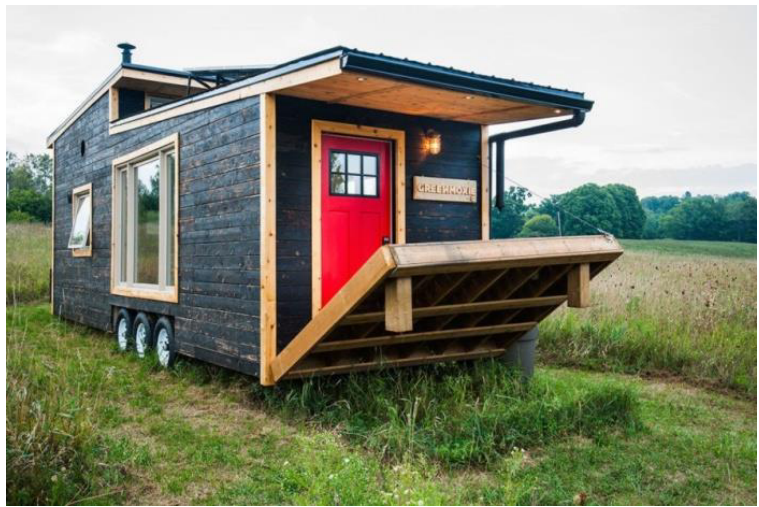

Fig. 3. Greenmoxie Tiny House, general view

\section{Anderson Mobile Estates [14]}

It should also be noted that the need for such homes is often fueled by many famous personalities whose lives are associated with a large number of movements and who have chosen this path for themselves - always and everywhere to stay in their home. For example, such actors as Ashton Kutcher, Sharon Stone and Vin Diesel, who ordered their homes from Anderson Mobile Estates 


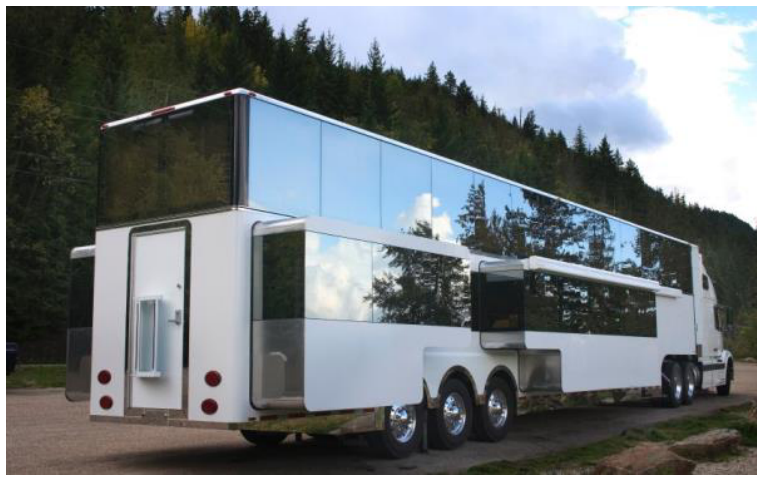

Fig. 4. Example of Anderson Mobile Estates, general view

An additional feature of projects implemented by Anderson Mobile Estates is their multicomponent volumetric transformation, which allows to significantly increase the volume of internal premises in operation mode and not to go beyond the dimensions of a standard vehicle in the mode of transportation.

\section{4. «Manned Cloud» $[15]$}

In this line, a separate line is based on promising developments based not on ground but air vehicles. An example of such solutions is the Manned Cloud project jointly developed by Jean-Marie Massaud and the French Aerospace Research Center ONERA (Office National d'Etudes et Recherches Aérospatiales). This hotel-airship is designed for 40 passengers and 15 crew members, has on board 20 cabins, a restaurant, salon, library, gym, spa, bar and terraces.

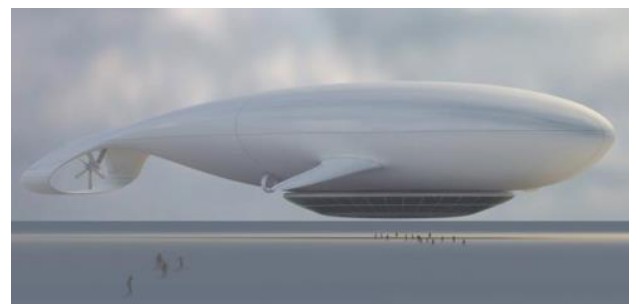

Fig. 5. Manned Cloud, general view

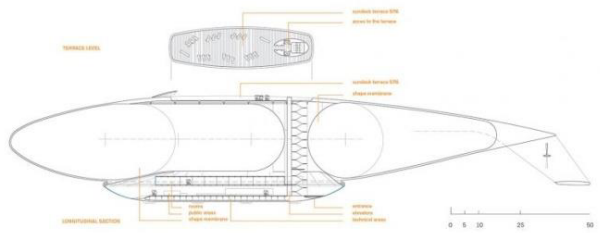

Fig. 6. Manned Cloud, basic technical solution

It should be given a brief description returning to the described project of a cluster mobile home. A mobile transformed residential cell of a cluster type consists of a system of transforming volume-spatial elements (blocks) performed in an open, closed or partially closed loop. In addition, there is a separate set of transverse elements (membranes) for forming a closed loop or separating of the internal space in the process of installation between individual open-type units or their groups. 
Blocks of an open type are designed for forming the base of the mobile home. Blocks of a partially closed type - for inclusion of individual functional blocks of increased factory readiness (for example, sanitary units, cabins) in the structure of the house, Closedtype blocks are mainly technological elements (blocks of autonomy, energy supply and other necessary resources) full factory readiness.

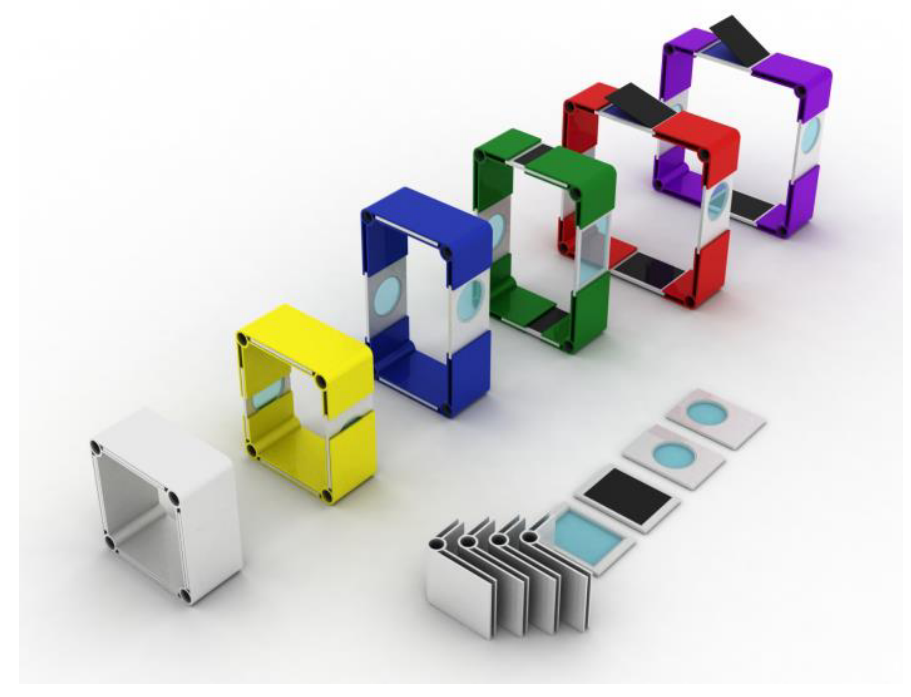

Fig. 6. Transformation of an element by the example of an open type block (A.V. Panfilov (C)

It is noted that each unit can be manufactured in monofunctional and in polyfunctional design. In the first variant the unit is delivered with assembled (or partially assembled) functional set (furniture, equipment, etc.). In the second case, it is possible to independently fill the internal space at the request of the owner.

Each block has outside measurements that correspond to the possibilities of highquality exploitation and movement. So in the transported state they have dimensions $1.6 \times 1.6 \mathrm{~m}$, which allows them to be moved element-by-element by any kind of trailers for passenger transport and moved on location without using of heavy equipment. In the operational position, the size increases to $3.2 \times 3.2 \mathrm{~m}$, which corresponds to the spatial human ergonomics. The width of the unit of reception is equal to $0.8 \mathrm{~m}$, Which also corresponds to modern requirements for ensuring the comfort of space and ease of movement. The system also includes blocks of increased width $(1.6 \mathrm{~m})$ and a reduced width $(0.4 \mathrm{~m})$, for accommodation of larger and smaller equipment, respectively.

The construction of the cell allows for hot-swapping, adding or removing of individual blocks during exploitation. 


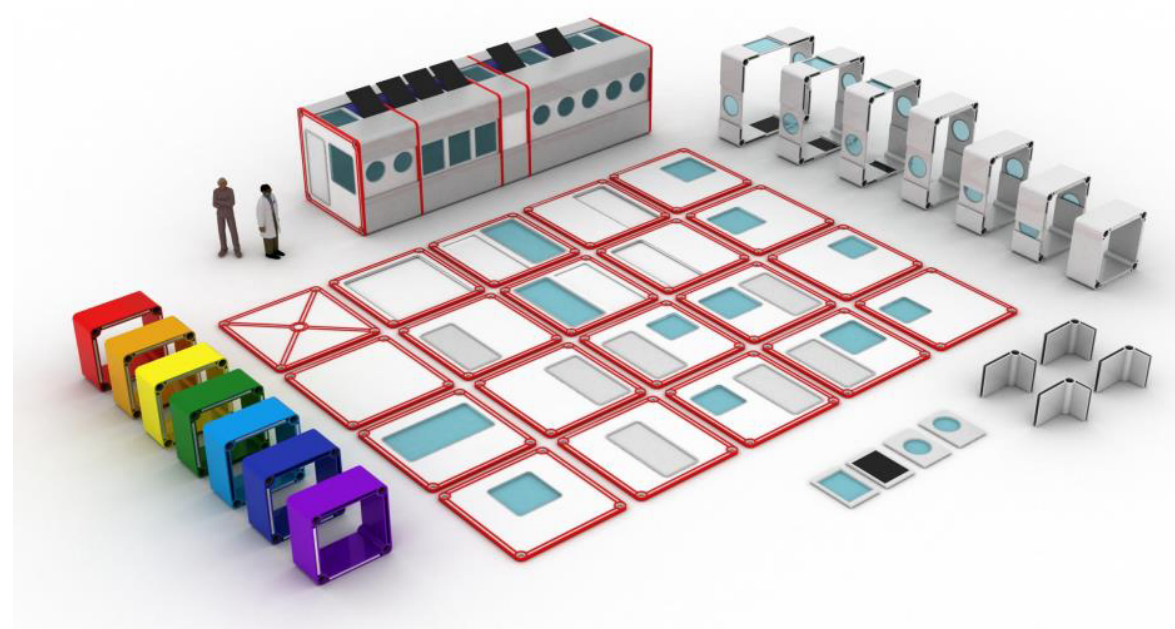

Fig. 7. An example of a set (home-kit) of a residential cell of a cluster type (A.V. Panfilov (C)

The project provides that there are sections of communications and engineering networks in each block, which in the process of linking blocks into a single building are connected to each other and they fasten the blocks into a single structural circuit by means of a locking element (electromagnetic, vacuum, etc.). In this case, the option of using an electromagnetic lock seems to be more optimal due to the possibility of switching off individual circuits for inserting or removing individual blocks. However, it is inferior to vacuum locks in terms of the degree of energy dependence and the density of contiguity to the elements to each other.

\section{Principal decisions related to its creation on the basis of additive technologies}

As an alternative to this project, it is possible to apply additive technologies (3D printing) [16-18] and individual elements of the supporting frame of blocks (in the solving the application of transformable blocks) or the whole block element in the event of a failure of the transformable configuration.

Using of additive production technologies in combination with parametric projection allows to solve a set of problems allowing to achieve the necessary qualitative characteristics that ensure the possibility of combining and recombining blocks:

- Accuracy of reproduction of elements and their separate parts;

- Accuracy and the possibility of introducing into the structure of a one unit of engineering network and communications elements;

- Shell formation of the one unit block taking into account the specified parameters of environmental extremes in operation mode; 
- The possibility of a constructive combination of different materials, both in terms of technical characteristics and in terms of their typology (metal, polymers, foam and fiber aggregates, etc.) in a single system;

- The possibility of structural integration of elements of internal design (furniture, equipment) into a single design with a bearing contour of the block;

- Thus, the above listed positions allow us to talk about the beginning of the formation of fundamentally new approaches to the creation of residential cells, the possibility of using them under the condition of the emergence of a sufficient level of demand is quite broad: recreation, alternative or second dwelling of a citizen, expeditionary and research activities, Oil companies a comfortable home that meets all modern requirements.

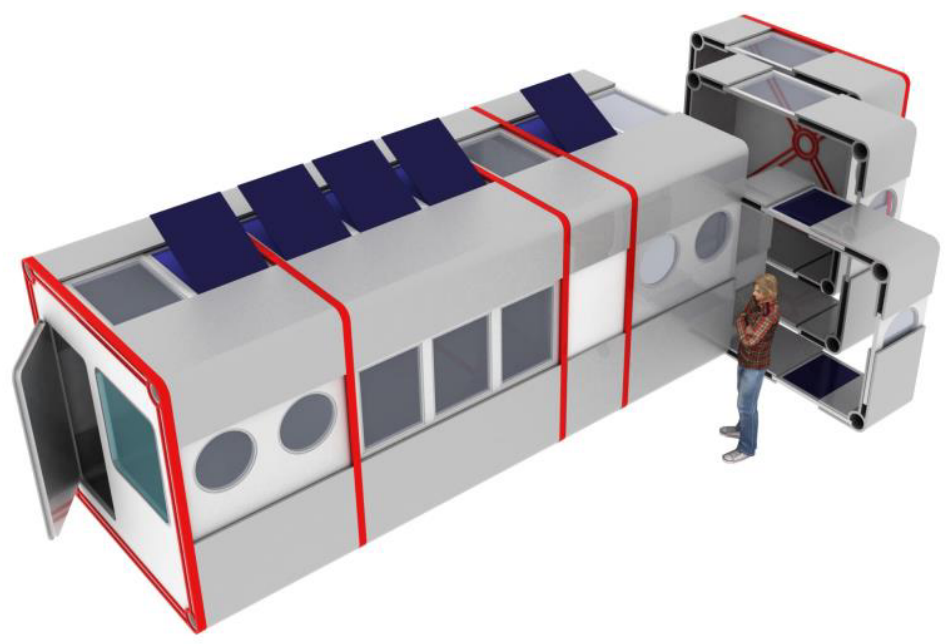

Fig. 8. Mobile residential cell. General view during assembly and reconfiguration (A.V. Panfilov (C)

At the same time, the present and perspective possibilities of using additive technologies allow to talk about the potential for using various kinds of local materials (earth, sands, etc.) and production waste (sawdust, slag, foam concrete) as the basic material of the supporting framework provided that an environmentally safe and weatherproof binder. In addition to this postulate, you can add the possibility of forming on this basis of expedition modules for the creation of bases and settlements in places where the possibility of delivery of finished equipment, buildings and structures is difficult or impossible. These can be represented by the Polar, Arctic and mountain territories, territories remote from traditional human habitats over considerable distances, including the exploration of outer space. 


\section{References}

1. Schmitt G.N.A., Duarte J.P. Future Cities : proceedings of the 28th Conference on Education in Computer Aided Architectural Design in Europe, September 15-18, 2010, Zurich, Switzerland, ETH Zurich / G.N.A. Schmitt, J.P. Duarte, vdf Hochschulverlag AG and der ETH Zürich, 2010. 257-264 c.

2. Jacque Fresco, Roxanne Meadows. Designing The Future. - The Venus Project, Inc, 2007.

3. Vitrenko Andrii. The Essence of Intangible Service as a Special Theoretical Category in the Modern Post-industrial Economics System. Procedia Economics and Finance 27 (2015). Elsevier. 2015. 267-273c.

4. Feldman, V.P., Audretsch D.B. Innovation in Cities: Science based Diversity, Specialization and Localized Competition-European Economic Review. - 1999. - № 43. - P. 409-429.

5. Landry C. Creative City. - Moscow: Publishing house "Classics-XXI, 2011. - 399p.

6. Saprykina, N.A. Utopian design of the 20th century. Futurological concepts of forecasting // "FUNDAMENTAL RESEARCHES of RAASN on the scientific provision of development of architecture, town-planning and construction industry of the Russian Federation in 2011" // Scientific works of RAASN, vol. 1, Moscow, 2012. - P. 262-267.

7. Hunt J. Architecture in the "cybernetic era" // Architectural Design. - № 11-12 / 1998 Retrieved from: http://www.i-home.ru/site.xp/0490550480501240 51056049055124.html

8. Virilio P. Information bomb. Strategy of deception. Translation from Fr. I. Okuneva. M.: "Gnosis", "Pragmatics of Culture", 2002. -192 p.

9. Panfilov A. The Cluster Model of Development of the City - MATEC Web Conf. 73 06008 (2016). DOI: 10.1051/matecconf/20167306008

10. Panfilov A.V. Mobile home: on the road from mobile to self-adaptive // Collection of scientific works SWorld. Materials of the International Scientific and Practical Conference "Modern Directions of Theoretical and Applied Research" 2013 ". Return 1. Volume 43-Odessa: KUPRIENKO, 2013 C. 81-93

11. Panfilov, AV Evolution, features of development and classification bases for the formation of mobile homes for temporary stay / A. V. Panfilov // Electronic Journal AMIT № 4 (17), 2011. (No. of state registration 0421100089): Retrieved from http://marhi.ru/AMIT/2011/4kvart11/panfilov/panfilov. Pdf, free. - Heading. From the screen..

12. Volkner Mobil Retrieved from http://www.volkner-mobil.com/perfgalgarage.$h t m l$

13. Greenmoxie Retrieved from https://www.greenmoxie. com/tiny-house

14. Anderson Mobile Estates Retrieved from http://andersonmobileestates .com

15. Manned Cloud Retrieved from http://www.massaud.com/node/386

16. Gibson, I., Rosen, D. W., \& Stucker, B. Additive Manufacturing Technologies. Additive Manufacturing Technologies 2010 (pp. 17-40). https://doi.org/10.1007/9781-4419-1120-9

17. Hopkinson N., Hague R.J.M., Dickens P.M. Additive Manufacturing Technologies for the Construction Industry. Rapid Manufacturing An Industrial Revolution for the Digital Age, 2006. (pp. 249-273). https://doi.org/10.1002/047 0033991.ch17

18. Fusero, P., Massimiano, L., Tedeschi, A., \& Lepidi, S. (2013). Parametric Urbanism: A New Frontier for Smart Cities. Planum The Journal of Urbanism, 2(27), 1-13. Retrieved from http://www.planum.net/planum-magazine/ themes-online/parametricurbanism-a-new-frontier 